\title{
Formation of Pyro-products by the Pyrolysis of Monobromophenols
}

\author{
Yuncheol Na, Jungju Seo, and Jongki Hong* \\ Hazardous Substance Research Team, Korea Basic Science Institute, Seoul 136-701, Korea \\ Received March 20,2003
}

\begin{abstract}
Thermal behavior of bromphenols was investigated by direct py rolysis at high temperature. The thermal degradation products formed by the pyrrolysis of mono-bromophenols $(o-m-$. and $p$-) were identified by gas chromatography-mass spectrometry. During the pyrolysis reactions. several kinds of dioxins and furans were produced and the relative ratio of pyro-products was dependent on the substituted position of bromine in phenolic structure due to the effect of stimmetry and steric hindrance. The formation of dioxins can be explained by the phenoxy radical addition and $\mathrm{Br}$ atom elimination at an ortho-carbon site on phenolic stnicture. On the other hand. the formation of furans can be explained by the ortho-ortho carbon coupling of phenoxy radicals at unsubstituted sites to form $0,0^{\prime}$-dihydroxydiphenyl intermediate via its keto-tautomer. followed by $\mathrm{H}_{2} \mathrm{O}$ elimination. The py roly'sis temperature has also a substantial effect on the dimerized products quantities but little effect on the type of py ro-products. Moreover, the formation mechanism of pyro-products was suggested on the basis of products identified.
\end{abstract}

Key Words : Py̆rolysis, Bromophenols. GC/MS, Formation mechanism

\section{Introduction}

Interest in thermal studies on bromophenols is justified by the extensive application of these materials in industrial process and by the central role in a wide range of chemical and biochemical reactions. ${ }^{1-3}$ Recently, polybrominated chemicals including bromophenols are widely used as an antiseptic. germicide and flame retardant in various industries. ${ }^{4}$ However. such brominated phenolic compounds are known for precursors in the formation of dibenzo-p-dioxins and furans via the formation of ether bonds during the industrial processes at high temperature. It was already reported that several types of chlorinated dioxins are produced when chlorinated phenols are py rolyzed for a few minutes at 300 $500^{\circ} \mathrm{C}^{5.6}$ The formation mechanism of polychlorinated dibenzodioxins and furans (PCDD/Fs) from chlorophenols were already proposed by Born et al ${ }^{7 \delta}$ Furthermore. temperature dependence of $\mathrm{PCDD} / \mathrm{Fs}$ isomer distribution has been intensively studied by semi-emprical molecular orbital methods." Similarly brominated dioxins can be generated during the pyrolysis of brominated phenolic compounds. The combustion of brominated flame-retardants of various compositions is also interest in formation of polỵbrominated dioxins.

Recently. Sidhu et al ${ }^{\text {lo }}$ has proposed the reaction kinetic models on the formation of tetrachloro- and tetrabromodibenzo-p-dioxins from the pyrolysis of 2.4.6-trichlorophenol and 2.4.6-tribromophenol respectively: Moreover. thermal behavior of bromophenols in the presence of eicosane ${ }^{\mathrm{ll}}$ has been studied on the aspect of mechanistic tools. Photoreaction mechanism of 2-bromophenol in lowtemperature argon matrices has been also investigated by

\footnotetext{
Author to whom contespondence should be addressed. Tel: +82-
} 2-920-0790, Fax: +82-2-920-0789; e-mail: jongki áa kbsi.te.kr low-temperature infrared spectroscopy. ${ }^{12}$ Although the py rolysis of 2-bromophenol has been already studied. ${ }^{\text {ll }}$ the pyrolysis of 3 - and 4-bromophenols has not been studied in detail. The position of bromine atom in phenol ring during the py rolysis can affect the type of pyro-products of bromophenols. Therefore. it is important to study the thermal behavior of bromophenols with different $\mathrm{Br}$ positions at high-temperature for the understanding of formation of dioxins and furans.

In this study. several pyro-products formed by the pyrolysis of $o-, m$ - and $p$-bromophenols. respectively. are identified by gas chromatography/mass spectrometry and the type of pyro-products are compared. The formation mechanism of py ro-products of corresponding bromophenols is proposed on the basis of products identified.

\section{Experimental Section}

Monobromophenols were purchased from Aldrich (Milwaukee. WI. USA) and their purities were of $99 \%$. All solvents used in this study were pesticide residue grade and obtained from J. T. Baker (Plillisburg. NJ. USA). Alumina used as clean-up column was purchased from Supelco (Bellefonte, PA, USA).

Reaction tubes $(5-6 \mathrm{~cm})$ were prepared by sealing one end of borosilicate glass Pasteur pipets. About $0.5 \mathrm{mg}$ of each bromophenol was inserted into the reaction tube. whose both ends were packed with glass wool. The tip of the reaction tube was flame sealed and then placed into a muffle furnace when nitrogen gas was allowed to flow at a rate of $100 \mathrm{~mL} /$ min. The furnace temperature was initially $100^{\circ} \mathrm{C}$. held for $10 \mathrm{~min}$ and then increased to 200.300 .400 and $500^{\circ} \mathrm{C}$ for $15 \mathrm{~min}$. The reaction tube was removed from the furnace and allowed to cool to ambient temperature. It was opened and contents were thoroughly rinsed out with $100 \mathrm{~mL}$ of 
methylene chloride by ultra-sonicator. The extract was concentrated to about I $\mathrm{mL}$ by rotary evaporator and $\mathrm{N}_{2}$ gas purge.

Gas Chromatography/Mass Spectrometry (GC/MS). An Agilent GC/MS system consisted of a model Agilent 6890 gas chromatograph and Agilent 5973 Network mass spectrometer (Jalo Alto, CA, USA) was used. A DB-5ms cross-linked 5\% phenyl methylsilicone fused-silica capillary column ( $30 \mathrm{~m} \times 0.25 \mathrm{~mm}$ l.D. $0.25 \mu \mathrm{m}$ film thickness) was used. The column was directly interfaced to the ion source. The oven temperature was initially $80^{\circ} \mathrm{C}$ (held for $10 \mathrm{~min}$ ). increased at $10^{\circ} \mathrm{C} / \mathrm{min}$ to $300^{\circ} \mathrm{C}$ (held for $5 \mathrm{~min}$ ). Samples (1 $\mu \mathrm{L}$ ) were injected in the splitless mode. The carrier gas was helium $(99.999 \%$ ) at $1.0 \mathrm{~mL} / \mathrm{min}$ and column head pressure at 9.3 psi. The electron impact source was operated at $70 \mathrm{eV}$. The injection port transfer line and ion source temperatures were set at 280,230 , and $280^{\circ} \mathrm{C}$, respectively.

\section{Results and Discussion}

The pyrolysis of bromophenols could produce several kinds of compounds via diverse reaction pathways. The previous study ${ }^{13}$ has shown that the thermal reaction of chlorinated phenols resulted in the formation of dioxin isomers, with isomer distributions affected by steric effect associated with $\mathrm{Cl}$ substitution. Furans could be also formed through condensation of intermediates produced during pyrolysis of chlorophenols. In this study, the pyrolysis of each monobromophenol was performed at different temperatures $200,300,400$, and $500^{\circ} \mathrm{C}$, respectively. The relative abundance of three bromophenols was plotted against pyrolysis temperatures, as shown in Figure I. No thermal degradation of bromophenols was observed at $200^{\circ} \mathrm{C}$. The degradation of 2-bromophenol was more rapid at $300^{\circ} \mathrm{C}$ than those of 3-and 4-bromophenols because of its relatively low boiling point and high reactivity of om tho-bromine. All bromophenols were completely degraded and transformed into pyro-products at $400^{\circ} \mathrm{C}$ and $500^{\circ} \mathrm{C}$.

Typical mass spectra of pyro-products formed by the

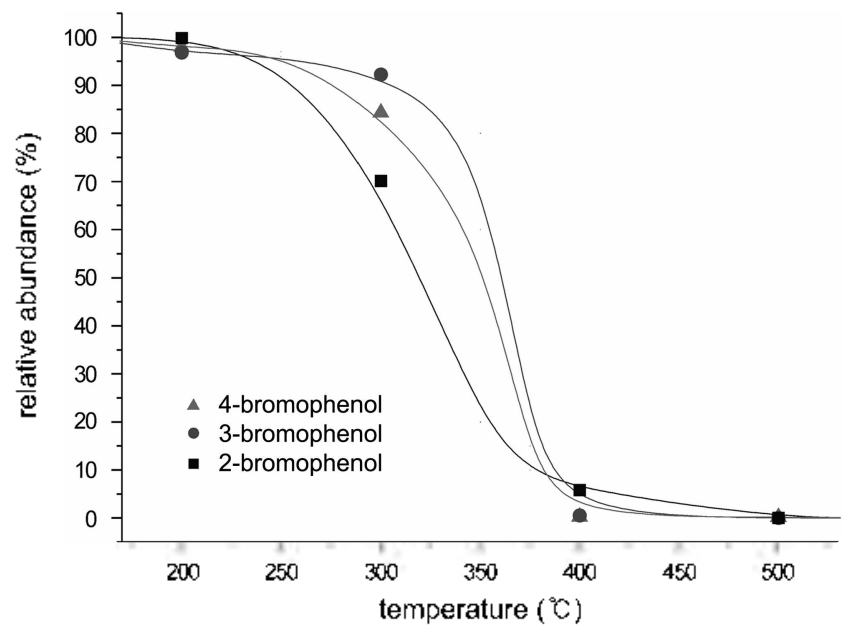

Figure 1. Thermal decar curves of monobromophenols (o-. $m$ - and $p$-) against pyroly sis temperatures.
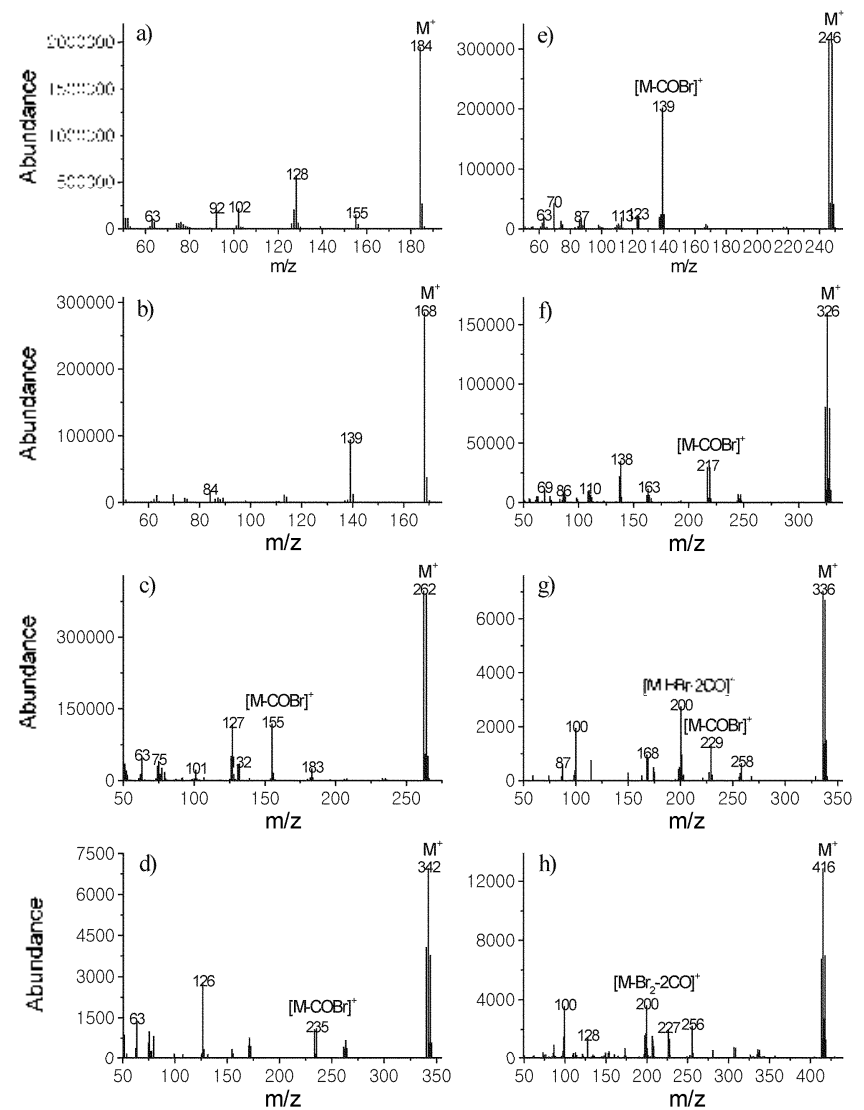

Figure 2. Typical mass spectra of dimerized products formed by the pyrolysis of monobromophenols. (a) dibenzodiosin. (b) dibenzolutan. (c) monobyomodibenzodioxirn. (d) dibromodibernodioxin. (e) monobromodiben\%oluran. (1) dibromodibencotiran. (g) monobromobenzobisbenzofiran. and (h) dibromobenzobisbenzofuran

pyrolysis of bromophenols were indicated in Figure 2. The molecular and fragment ions of brominated dioxins and furans exhibited the typical, expected clustering due to the bromine isotopes. Brominated dioxins and furans were easily identificable from these El mass spectra by molecular ion and bromine number. Moreover, the presence of characteristic ions such as $\left|\mathrm{M}-\mathrm{COBr}^{-}\right|^{-}$ion and doubly charged ion $|\mathrm{M}|^{+-}$ could help for determination of the structure of brominated

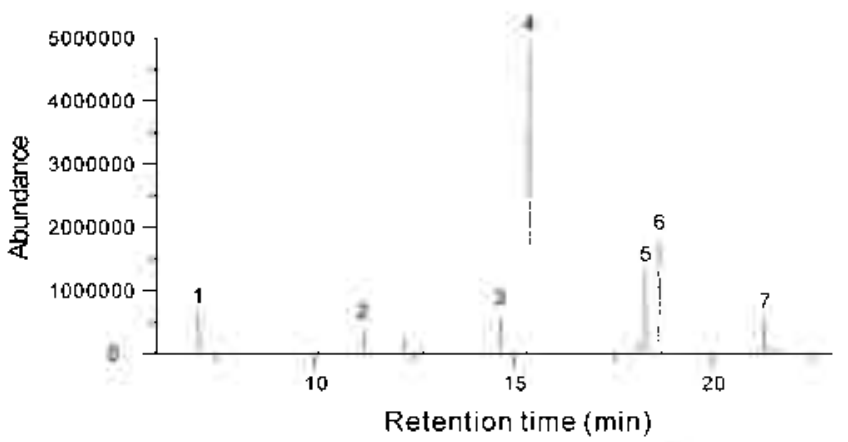

Figure 3. Total jon chromatogram of pyro-products lormed by the pyrolysis ol 2-bromophenol al $400^{\circ} \mathrm{C}$ for $10 \mathrm{~min}$. Peaks identity as follows: I. 2-bromophenol. 2. 4-bromophenol. 3, dibenzoturan. 4. dibenzodioxin. 5. 4-bromodibenzofuran. 6. 1-bromodibenzodioxin. and 7. 4.6-dibromodibenzofuran. 


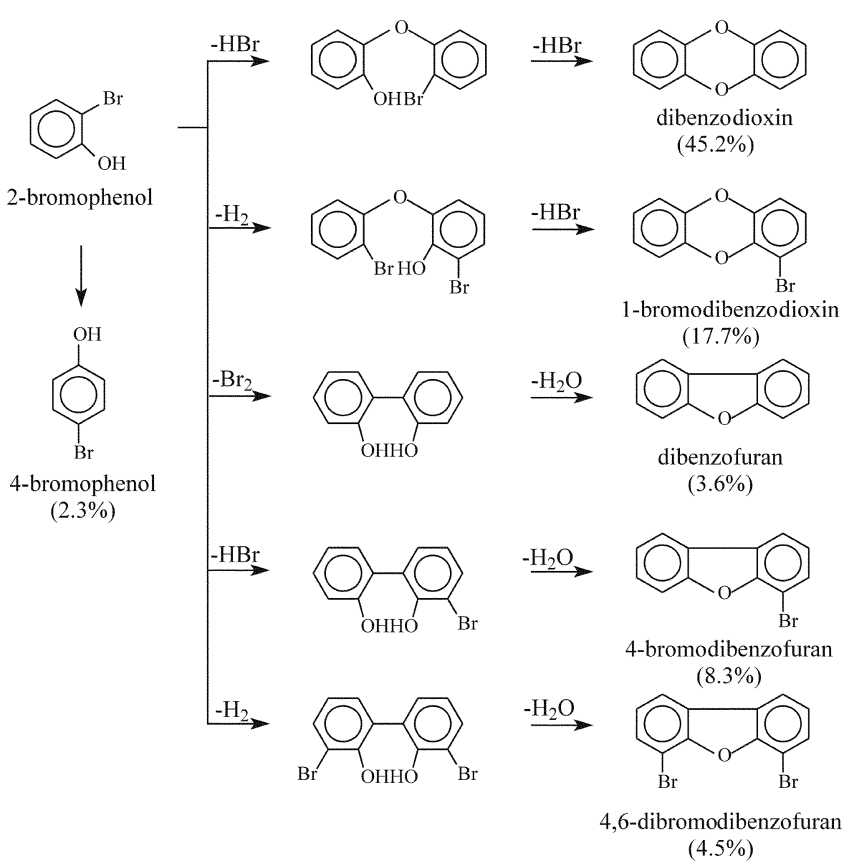

Scheme 1. lormalion pathways of pyro-porducts by the pyrolysis of 2-bromophenol.

dioxins and furans. The fragmentation pattems of these compounds were almost similar to those of chlorinated dioxins and furans.

Typical total ion chromatogram (TIC) of pyro-products formed from the pyrolysis of o-bromophenol at $400^{\circ} \mathrm{C}$ for 10 min was shown in Figure 3. Six major products were observed during pyrolysis and also unreacted 2-bromophenol was detected. These main products were 4-bromophenol, dioxin, furan, l-bromodioxins, 4-bromofuran, and 4,6dibromofuran. The possible formation mechanism of these products was more clearly indicated in Scheme I. The formation of dioxin from the pyrolysis of 2-bromophenol was already known by previous reports ${ }^{[0.11}$ that dioxins were formed by loss of $\mathrm{HBr}$ from diphenylether intermediates produced by self-condensation. On the other hand, the formation of furans was resulted in loss of $\mathrm{H}_{2} \mathrm{O}$ from dihydroxybiphenyl intermediates. Interestingly, a part of 2bromophenol was converted into isomeric product, 4bromophenol, during pyrolysis process. This observation indicated that 2-bromophenol could loose bromine radical to form phenolic radical intermediate and then bromine radical attacked at para-position of phenolic radical to form 4bromophenol. The bromine transfer from 2-postion to 4position has also observed in the photoreaction of 2bromophenol. ${ }^{12}$

The formation of I-bromodioxin could explain that two hydrogen radicals from ortho-position and hydroxyl group. respectively, were preferentially lost during the condensation of 2-bromophenol and then loss of $\mathrm{HBr}$ molecule from dibromo-, hydroxydiphenylether intermediate. For 4-bromofuran and 4,6-dibromofuran, the loss of $\mathrm{HBr}$ and $\mathrm{H}_{2}$ molecules, respectively, were taken placed and then dehydration reaction from their intermediates was occurred, as shown in

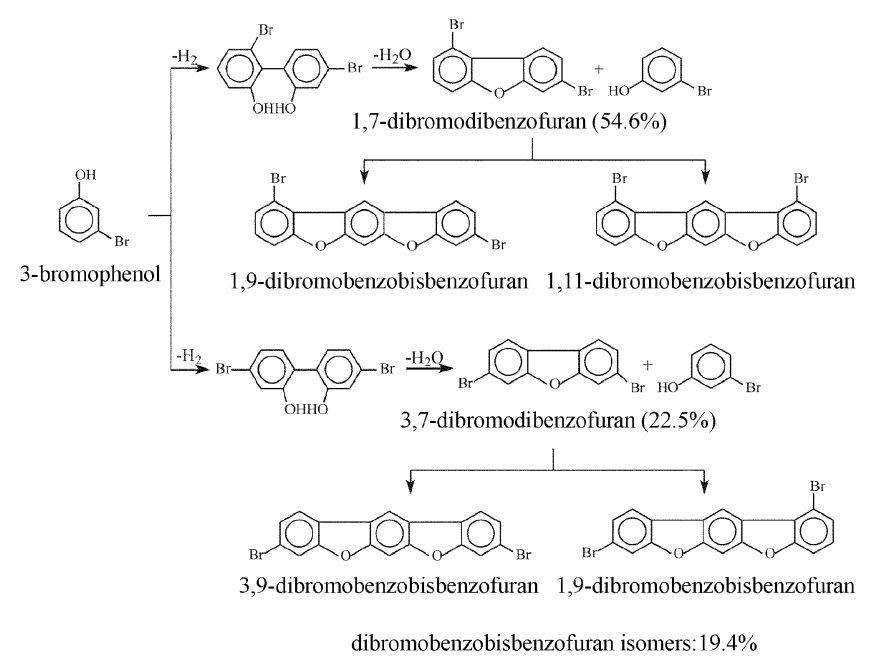

Scheme 2. Formation pathways of pyro-porducts by the pyrolysis of 3-bromophenol.

Scheme I.

The pyrolysis of 3-bromophenol led to produce two kinds of pyro-products such as two dibromofuran isomers and three dibromobenzobisbenzofuran isomers, as shown in Figure 2. Two dibromfuran isomers could be assigned as 1,7and 3,7-isomers, respectively. The dibromobenzobisbenzofuran isomers could not be exactly assigned because of the lack of authentic standard. The formation of dibromofurans could explain that once $o_{0} o^{\prime}$-dihydroxy-biphenyl intermediates were formed by the loss of two or ho-hydrogen radicals and followed by dehydration, as indicated in Scheme 2. For dibromobenzohisbenzofuran isomers, possible four isomers could be formed by the condensation of dibromofuran and 3 bromophenol, as shown in Scheme 2. In this study, 3 isomers were observed as shown in Figure 2 , but it still remains a possibility that one isomer could not unresolved in TIC. No dibenzodioxin derivatives were observed under these experimental conditions.

Unlike 2- and 3-bromophenols, the pyrolysis of 4-bromophenol produced diverse products via condensation of several intermediates. Typical TIC of pyro-products obtained from the pyrolysis of 4-bromophenol at $400^{\circ} \mathrm{C}$ for $10 \mathrm{~min}$ was shown in Figure 3. Nine main products were observed and assigned as 1.4-dibromobenzene, dibenzofuran, 2bromodibenzofuran, 2-bromodioxin, 2,8-dibromofuran, 2.7dibromodioxin, tribromofuran, bromobenzobisbenzofuran, and dibromobenzobisbenzofuran.

Especially, the observation of 1,4-dibromobenzene indicated that both dehydroxylation and bromination reaction was simultaneously taken placed under the pyrolysis of 4 bromophenol. However, this product was not observed under the pyrolysis of 2- and 3-bromophenol. The main product, 2,8-dibromodibenzofuran, was formed by the elimination of two ortho-hydrogen radicals and followed by dehydration. The formation of 2-bromodibenzofuran could be explained by either the condensation of 4-bromophenol and phenol or debromination of 2.8-dibromodibenzofuran. Similarly, the sequentially thermal debromination of 2-bromodibenzofuran 


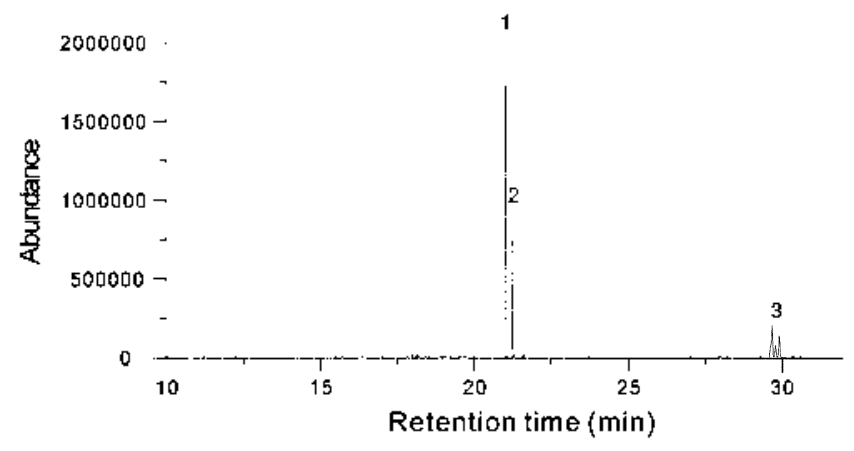

Figure 4. Total ion chromatogram of pyro-products formed by the peroly sis of 3-bromophenol at $400^{\circ} \mathrm{C}$ for $10 \mathrm{~min}$. Peaks identity as follows: 1. 1.7-dibromodibenzoluran, 2. 3.7-dibromodihencolurarn. and 3. dibromobenzobisbencofirans.

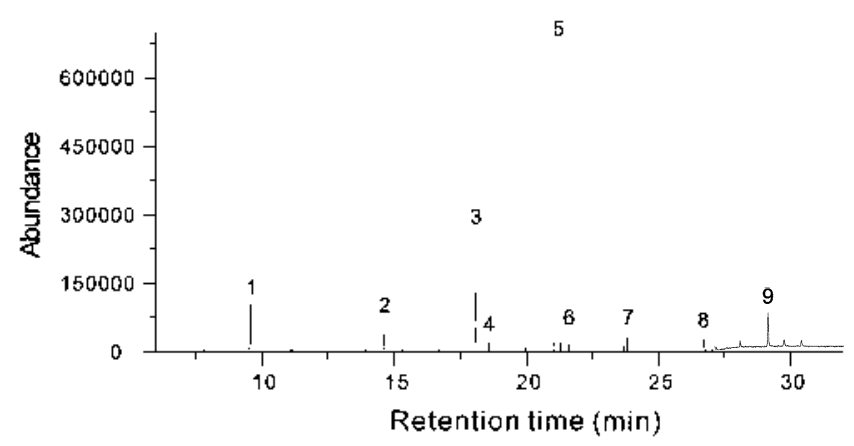

Figure 5. Total ion chromatogram of py ro-products formed by the prolysis of 4 -bromophenol at $400^{\circ} \mathrm{C}$ ' for $10 \mathrm{~min}$. Peaks identity as follows: 1, dibromobenzene 2, dibenzoluran. 3, 2-bromodibenzofuran. 4. 2-bromodibenzodioxín. 5, 2.8-dibromo-dibenzoturan. 6 . 2.7-dibromodibenzodioxin. 7. 2.4.8-tribromodibenzoturan. 8. 2bromo-benwobisbenzoluran, and 9. 2.11-dibromobenzobishenzofiuran.

formed from the debromination of 2,8-dibromodibenzofuran led to formation of dibenzofuran. The formation of oxidative bromination product, 2.4.8-tribromodibenzofuran, could be explained by two pathways. The one pathway is that $2,8-$ dibromodibenzofuran could be attacked by bromine radical which is initially produced during pyrolysis of 4-bromophenol. The other pathway is probably formed through the condensation of 4-bromophenol and I.4-dibromobenzene.

The dioxin products were also observed during the pyrolysis of 4-bromophenol. The formation of dibromodioxins could explain that bromo,hydroxydiphenylethers as intermediates was formed through the coupling bromophenoxy radicals and bromophenol, and followed by the removal of $\mathrm{H}_{2}$ molecule. The formation of tricyclic products could be explained by the condensation of dibromobenzofurans with 4-bromophenol, as indicated in Scheme 3.

In Figure 6 , the relative abundance of dimerization products based on the integrated area are plotted against pyrolysis temperatures. It was assumption that the response factors of products are all identical in $\mathrm{GC} / \mathrm{MS}$ analysis. All data points are the average of three measurements. As can be seen in Figure 6-(a) for the pyrolysis of 2-bromophenol, dibenzo-p-dioxin was formed much more rapidly than other compounds. Especially, the amounts of dioxin and furan

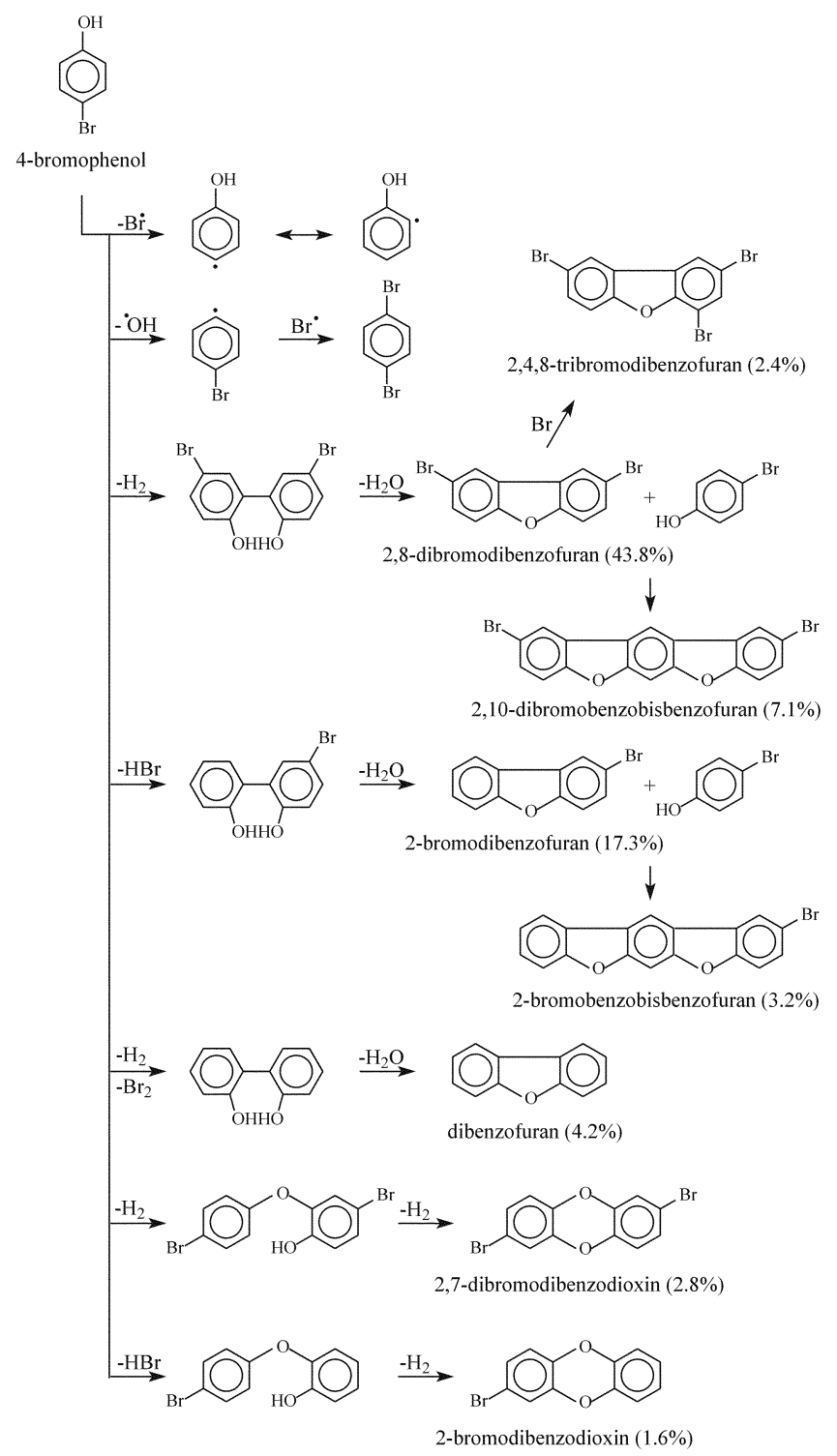

Scheme 3. Formation pathways of pyro-porducts by the pyrolysis of 4-bromophenol.

were gradually increased as pyrolysis temperature increased and the decay was not observed even at $500^{\circ} \mathrm{C}$. Whileas the formation of other products was relatively slow and the decay was observed above at $400^{\circ} \mathrm{C}$. In the pyrolysis of 3bromophenol [Figure 6-(b)], the amounts of 1,7- and 3,7dibromodibenzofurans was rapidly increased to $400^{\circ} \mathrm{C}$ but decreased at $500^{\circ} \mathrm{C}$. These compounds might be converted into debrominated products at $500^{\circ} \mathrm{C}$ by thermal degradation process. However, the amounts of dibromobenzobisbezofuran derivatives were slightly higher at $500^{\circ} \mathrm{C}$ than at $400^{\circ} \mathrm{C}$, indicating that condensation reaction continuously proceeded as temperature increases. In Figure 6-(c), all products produced by the pyrolysis of 4-bromophenol were shown similar trend which continued to increased up to $400^{\circ} \mathrm{C}$ and did not significantly changed to $500^{\circ} \mathrm{C}$. These products might be stable and less degradable even at $500^{\circ} \mathrm{C}$. 

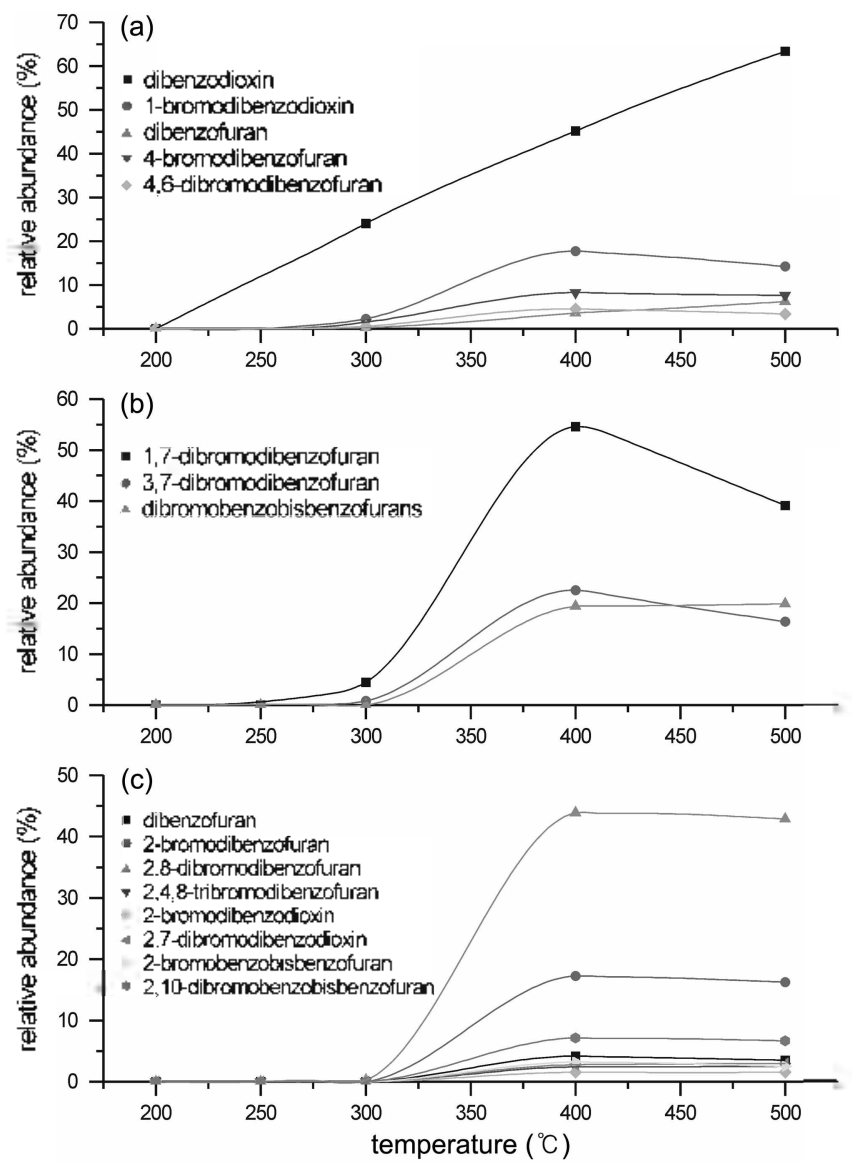

Figure 6. Formation curves of pyro-products formed by the puroly sis of monobromophenols [(a) 2-, (b) 3- and (c) 4-] against py roly sis temperatures.

\section{Conclusion}

The main products produced from the pyrolysis of each bromophenol are quite different due to different formation mechanism according to the position of bromine atom on phenol structure. Ortho-bromophenol mainly produced the dioxin products and not observed tricyclics such as benzobisbenzofuran derivatives. On the other hand, $m$ - and p-bromophenols mainly produced the furan products that were formed by ortho-ortho carbon coupling of phenoxy radicals at unsubstituted position. From ontho-ortho carbon coupling, $o, o^{\prime}$-dihydroxybiphenyl intermediate via ketotautomer once formed, and followed by $\mathrm{H}_{2} \mathrm{O}$ elimination to form furan products. Moreover, tricyclic products were formed by the condensation of dimerized products and bromophenol, during pyrolysis of $m$ - and $p$-bromophenols. The dioxin products were not observed for $m$-bromophenol but were formed as minor products for $p$-bromophenol.

Acknowledgement. This work was financially supported by Eco-2l program, the Ministry of Environment, Korea.

\section{References}

1. l'imentel. G. C.: McClellan. A. L. The Hydrogen Bond: Freeman: San Francisco. 1960.

2. Vinogradov. S. N.: I.innel. R. I., /ydrogen Bonding: varn Nostrand Reinhold: New York. 1971.

3. Schuster: P.: /undel. (i.: Sandorty: c. The /fydogen Bond: IIsevier: Amsterdam. 1976.

4. Lassen. C.: Lohke. S.: Hasen. L. I. Brominated Home Retardants. Miljoprojickt nr. 494: Danish Environmental Agency: 1999: p 240.

5. Webber. R.: Hagetunaicr. H. Chemosphere 1999. 38. 529549.

6. I long. J.: Yoo. J. S.: Chang. Y. S.: Park. J.: Kim. K. I. Bull. Noreon (he'm. Soe. 1995. 16. 79-81.

7. Bom. J. (j. l': Louw. R.: Mulder. L'. (hemosphere 1989. 19. 401406

8. Boml. I. G. P.: Muldor. P.: Louw. R. Enwron. Scr. Technol. 1993. 27. 1849-1863.

9. Mulholliund. I. A.: Akki. II.: Yang. Y.: Ry.u. J. Y. Chemosphere 2001. 42. 719.727 .

10. Sidhu. S. S.: Maqsud. L.: Dellinger. B. Combust. Fkme' 1995. 10\%. 11-20.

11. Borojovich. E. J. C.: Aizonshtatt. Z. J. Anal Appl. Pyrol. 2002. 63. 129-145.

12. Akai. N.: Kudoh. S.: Takayanagi. .V.: Nakattin M. Chem. Pinsics Let'ti. 2002.362.591-597.

13. Mulholland. J. A.: Lokke. S.: Hansen. L. I.: Rutledge. G. C. . Phes Chem. 1993. 97. 6890-6896. 